http://www.jfas.info

\title{
EXPERIMENTAL AND NUMERICAL INVESTIGATION ON BLAST WAVE PROPAGATION IN SOIL STRUCTURE
}

\author{
M. N. Hafizi ${ }^{1,2,{ }^{*}}$, M. S. Risby ${ }^{1}$, S. T. Umar ${ }^{1}$, M. F. M. Isa ${ }^{1}$, A. S. M. Sohaimi ${ }^{1}$ and S. Khalis ${ }^{1}$ \\ ${ }^{1}$ Protection and Survivability Research Unit (PROTECT), Faculty of Engineering, Universiti \\ Pertahanan Nasional Malaysia, Sungai Besi Camp, 57000 Kuala Lumpur, Malaysia \\ ${ }^{2}$ Centre for Defence Research and Technology, Universiti Pertahanan Nasional Malaysia, \\ Sungai Besi Camp, 57000 Kuala Lumpur, Malaysia
}

Published online: 10 September 2017

\begin{abstract}
This paper presents a study on blast wave propagation in a soil structure when subjected to a surface air blast loading. The experimental work utilized the use of plastic explosive of $1 \mathrm{~kg}$ weight (PE4) in order to create a spherical blast wave at a fixed standoff distance. The experimental results were then compared with the numerical simulation model computed using LSDYNA3D. Although the computed simulation and experimental results showed large difference in terms of values, but both results provide a similar trend in terms of blast peak overpressure.
\end{abstract}

Keywords: shockwave; detonation; ground; finite element analysis; peak overpressure.

Author Correspondence, e-mail: mohdhafizi@upnm.edu.my

doi: http://dx.doi.org/10.4314/jfas.v9i3s.19

\section{INTRODUCTION}

According to [1], underground structures can be categorized into two major types; (a) fully buried structures (b) partially buried structures. These sub ground level structures are made 
from materials such as metals, structural steel, high strength low alloy steel, reinforcing steel, high carbon content steel, concrete, timber, etc. However, the most common materials usually predominantly existed is soil structure which may comprised of sand, silt, and clay, rocks and minerals.

It is commonly known that if an explosion detonates on or above the ground region, the shock wave will propagate into the ground structure as a results from the energy transmitted to the ground by the blast explosion. A partial of the detonation energy is transferred through the ground as direct induced ground shock, whereas the remaining detonation energy is transferred out the surrounding air as air-induced ground shock.

According to [2], the best approach for predicting the underground wave can be obtained using the fluid-structure interaction (FSI) approach. FSI allows an approach to compute force, deformation rate, material strength and blast damage that caused by the blast wave. In numerical simulation approach, the methods for predicting the underground wave can be obtained without the reflection and refraction of the spatial wave on the soil. Furthermore, the neglect of spatial wave in the underground wave analysis can be produced using a simple analysis, but this computational process is only in one-dimensional wave propagation [3].

In a previous study, in [4] investigated the conservation laws on the underground wave using a numerous of soil types in the computer simulation. The determination of soil types was based on the elastic condition and the yield stress of the soil. The difference in the elastic condition and the yield stress delivers a different overpressure (ground shock).

Physically, the blast wave propagation on the soil can be classified into the body wave and the surface wave. Specifically, the body wave propagates into the soil, while the surface wave propagates on the soil surface. Historically, the common guidance for predicting the underground wave was a data sheet published by [2]. Furthermore, the data sheet consists of some investigation results of the body wave and the surface wave.

\section{RESULTS AND DISCUSSION}

The finite element simulation of spherical air blast impact to the ground surface is as shown in Fig. 1. Fig. 1(b) depicts the detonation initiation where the explosive is fixed at 1 meter above 
from the air-soil boundary (in $\mathrm{Z}$ direction). Fig. 1(c) shows the blast wave hit the soil boundary layer (ground surface) and reflective waves occurrence at the air boundary layer. Fig. 1(d) and (e) depicts the blast wave propagation into the deeper layer of the soil boundary condition and also reflective wave pressure reduction in air boundary.

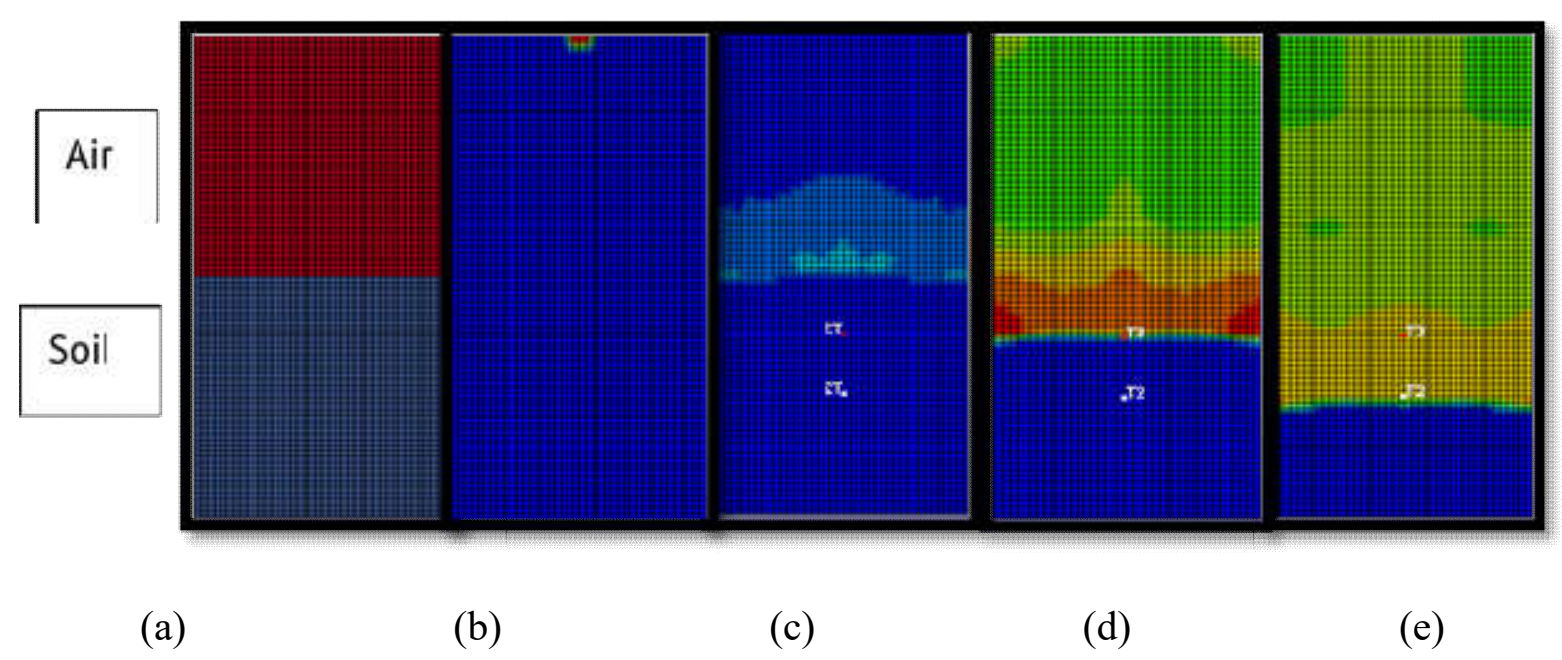

Fig.1. (a) Air and soil, (b) $0.0 \mathrm{~ms}$, (c) $2.01 \mathrm{~ms}$, (d) $20.17 \mathrm{~ms}$, (e) $40.39 \mathrm{~ms}$

Fig. 2 depicts the comparison between the experimental and simulated results of ground pressure at $0.25 \mathrm{~m}$ from the ground surface.

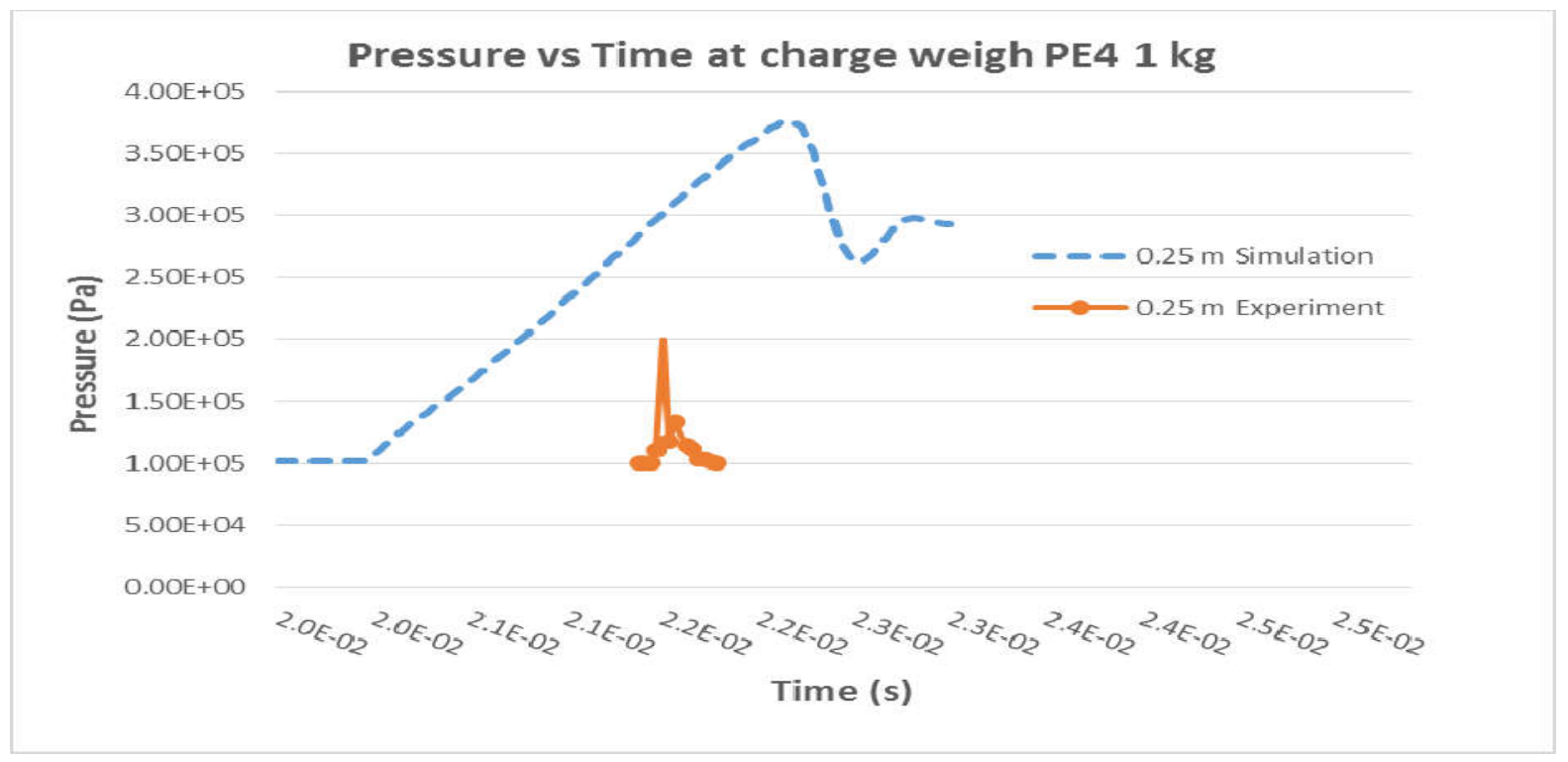

Fig.2. Peak pressure of experiment and simulation at $0.5 \mathrm{~m}$ from the surface

In the experiments, the air blast overpressure from 1-meter standoff distance was at $0.2 \mathrm{MPa}$ and $0.16 \mathrm{MPa}$ while the simulation data computed pressure at underground depth of 0.25 meter is $0.37 \mathrm{MPa}$ and $0.28 \mathrm{MPa}$ respectively. The larger difference in terms pressure values can be due from the noise or disturbance (error in instrumentation terms) that was recorded 
during the experiments. However, both curves showed similar trends in terms of pressure distribution. Fig. 3 depicts the comparison experimental and computed data of peak pressure for ground level of 0.5 -meter depth.

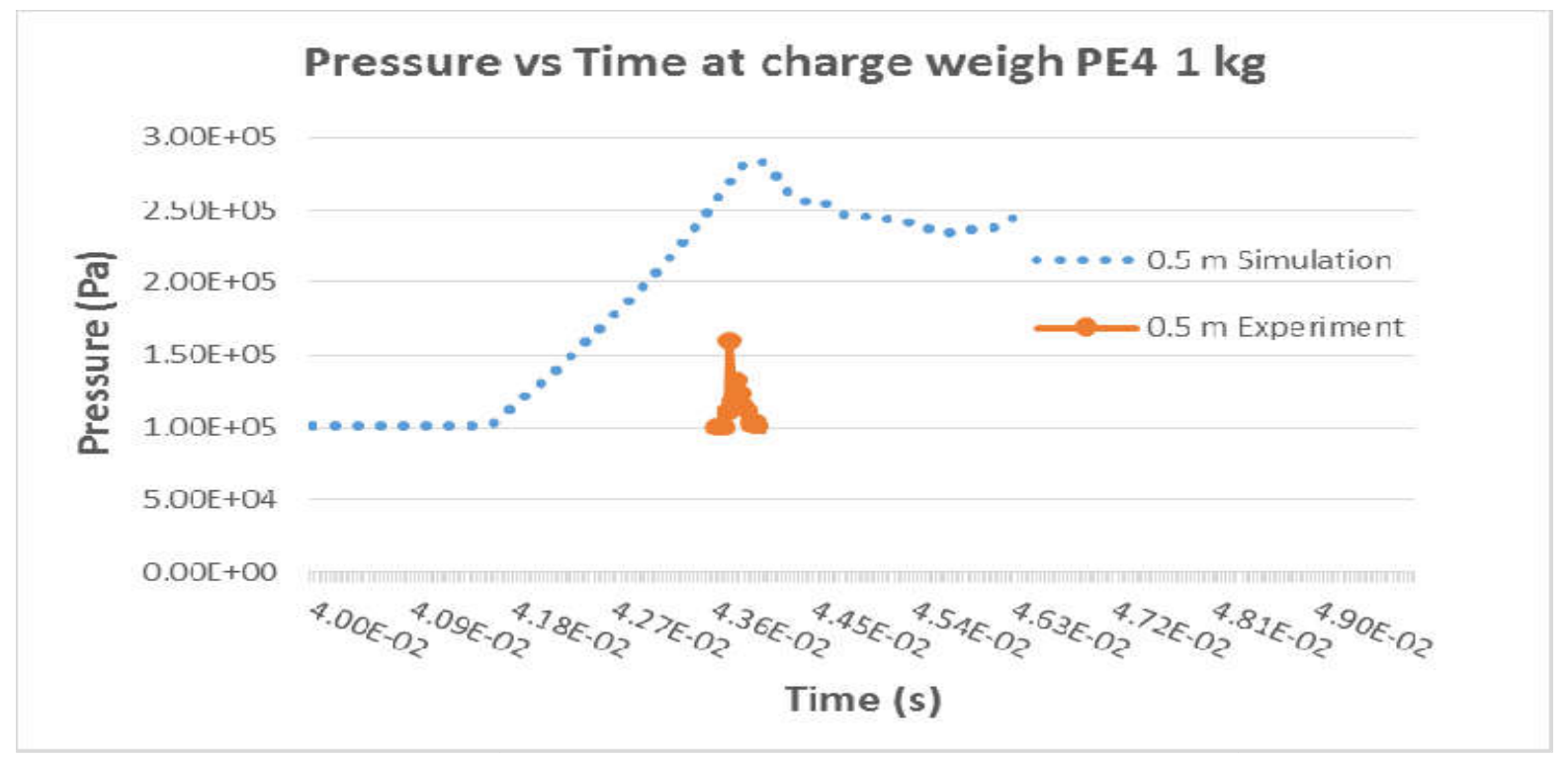

Fig.3. Peak pressure of experiment and simulation at $0.5 \mathrm{~m}$ from the surface

Fig. 4 shows the impacting force measured from the strain gages at 0.25 meter and 0.5 meter depth. Both force versus time curves show a similar trend, and this can be assuming that the spherical blast wave propagates through the soil in a uniform frequency or loadings.

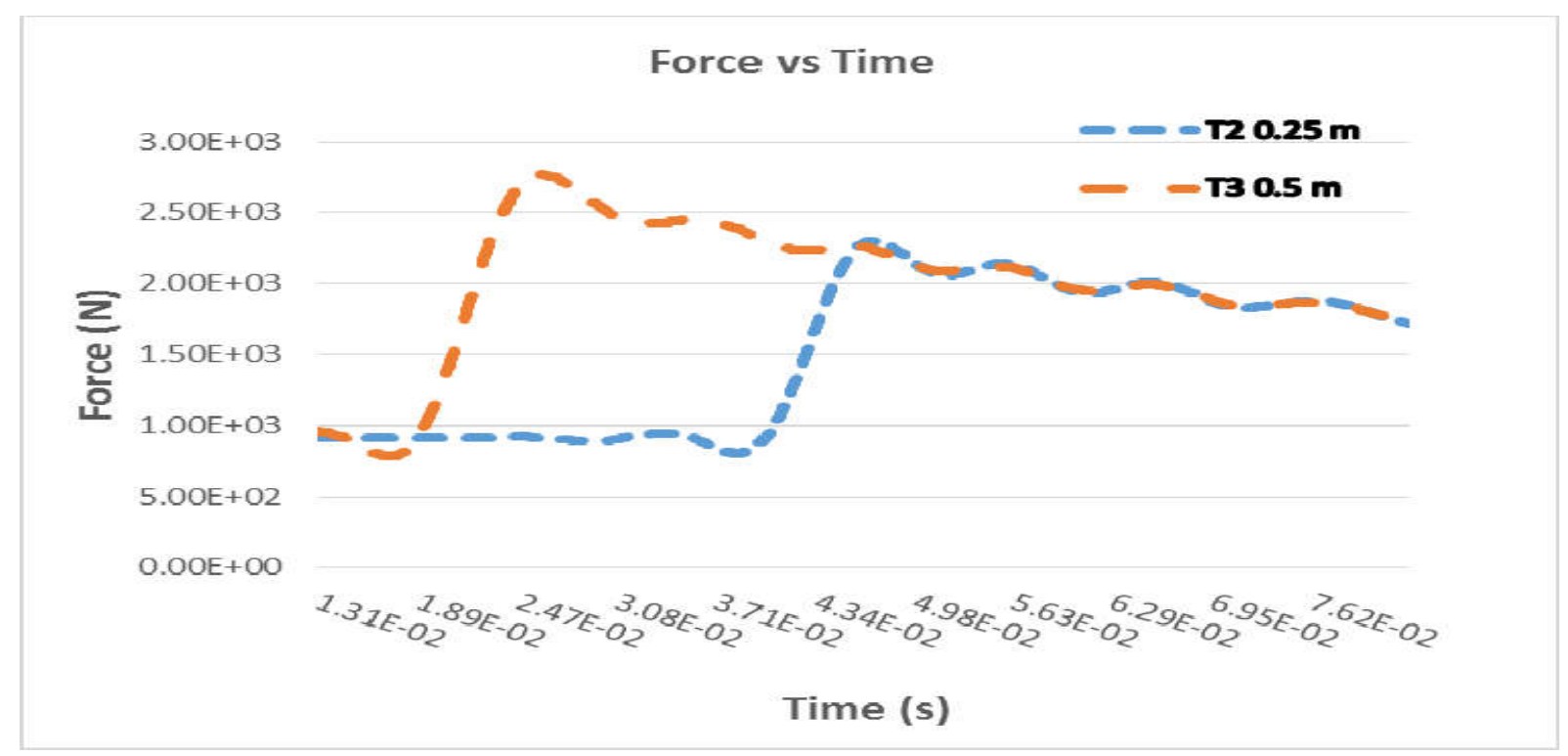

Fig.4. Force versus time curves at 0.25 meter and 0.5 meter depth

Other than that, air blast will produce the shock from the energy of explosive based on the acceleration the shock decrease as the distance increase as shown in Fig. 5. At the point 0.25 meter, the acceleration is $.76 \mathrm{e} 3 \mathrm{~m} / \mathrm{s}^{2}$ and at the point 0.5 meter the acceleration is $0.376 \mathrm{e} 3$ 
$\mathrm{m} / \mathrm{s}^{2}$. The decreasing because the energy reduces as the blast wave propagates deeper into the soil structure.

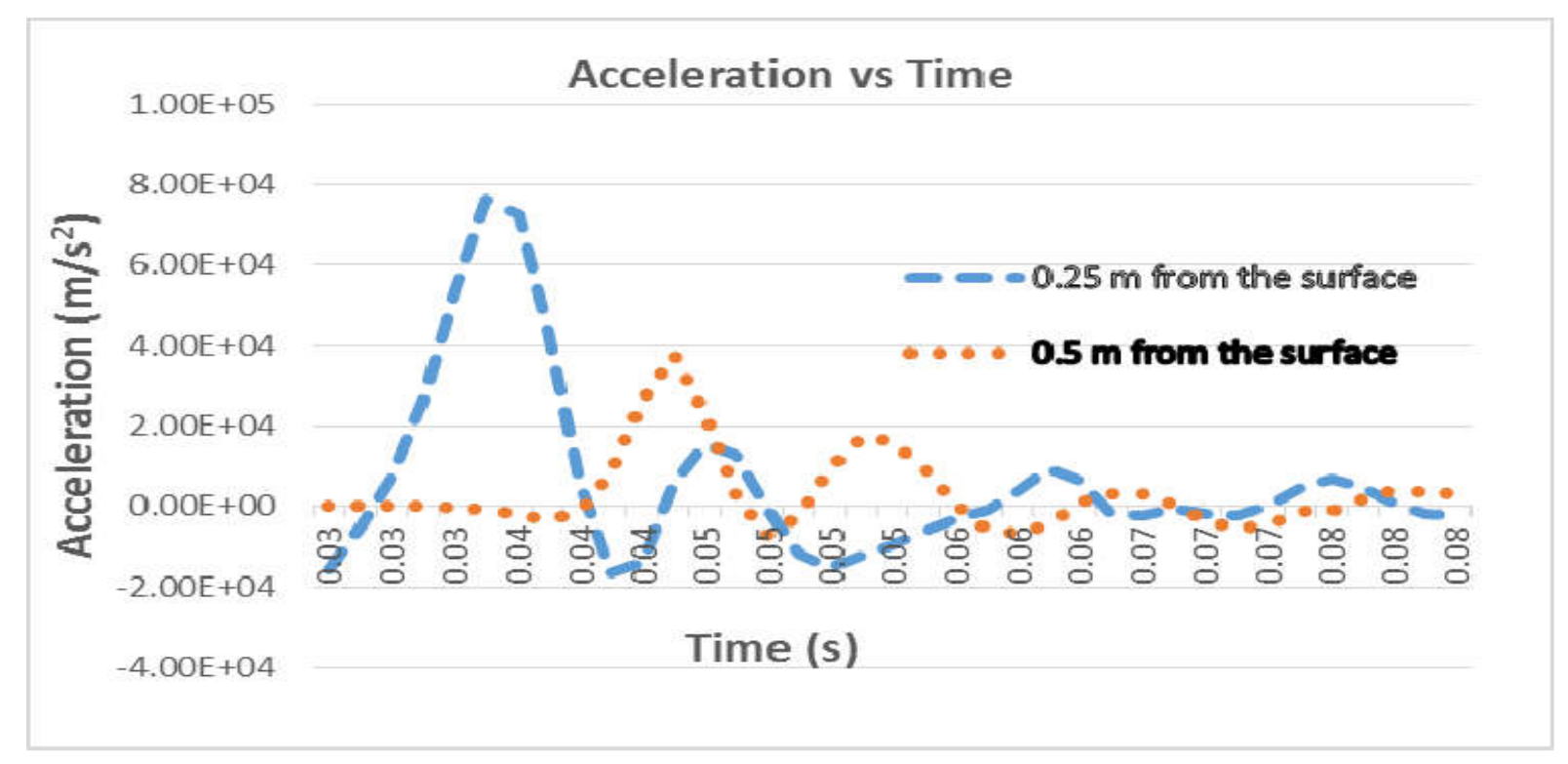

Fig.5. Acceleration at 0.25 and 0.5 meter depth

\section{EXPERIMENTAL}

\subsection{Page Layout}

When an explosive detonates, it produces a sudden rise in ambient pressure towards the surrounding including to the ground (as shown in Fig. 6) where the blast waves propagate into the ambient and into the ground

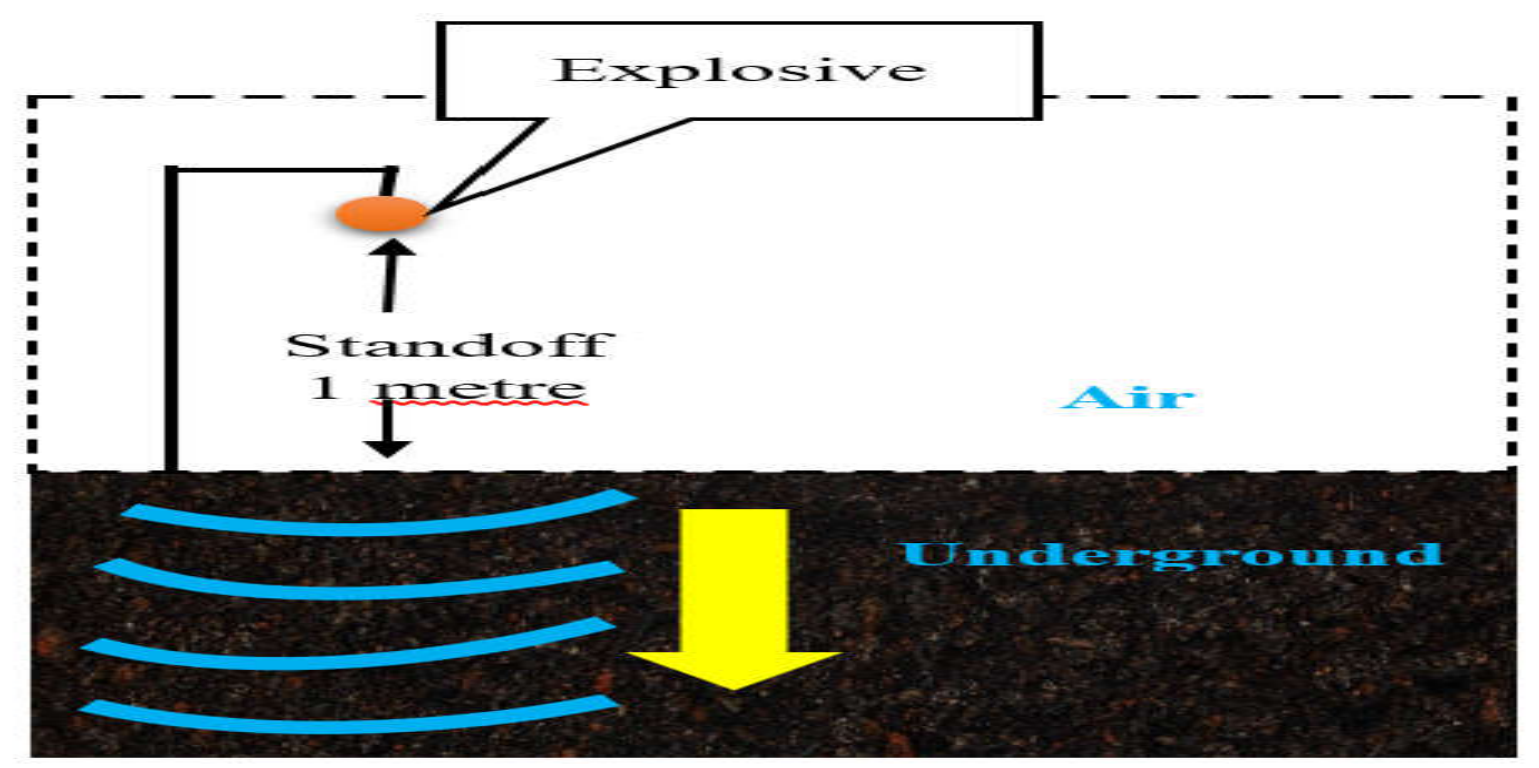

Fig.6. The blast wave propagates underground and ambient 


\subsubsection{Underground Wave Experimental Setup}

In this study, it is vital to measure the sudden movement of the soil due to the propagation of blast wave into the ground structure (as shown in Fig. 7). The underground wave response can be measured using strain gage, which is able to transform a ground response into a voltage unit and record using a high speed data acquisition system.

The purpose of this measurement is to estimate the impact force exerted to the soil layer during the blast event. This strain gages were fixed on a mild steel with a length of $0.15 \mathrm{~m}$ and width of $0.006 \mathrm{~m}$ (area of plate is $0.9 \times 10^{-3} \mathrm{~m}^{2}$ ). It is assumed that when the blast wave propagates through the ground, the sudden shift of the soil layer will bend the thin mild steel plate thus the impact force can be determined using conventional beam bending theory.

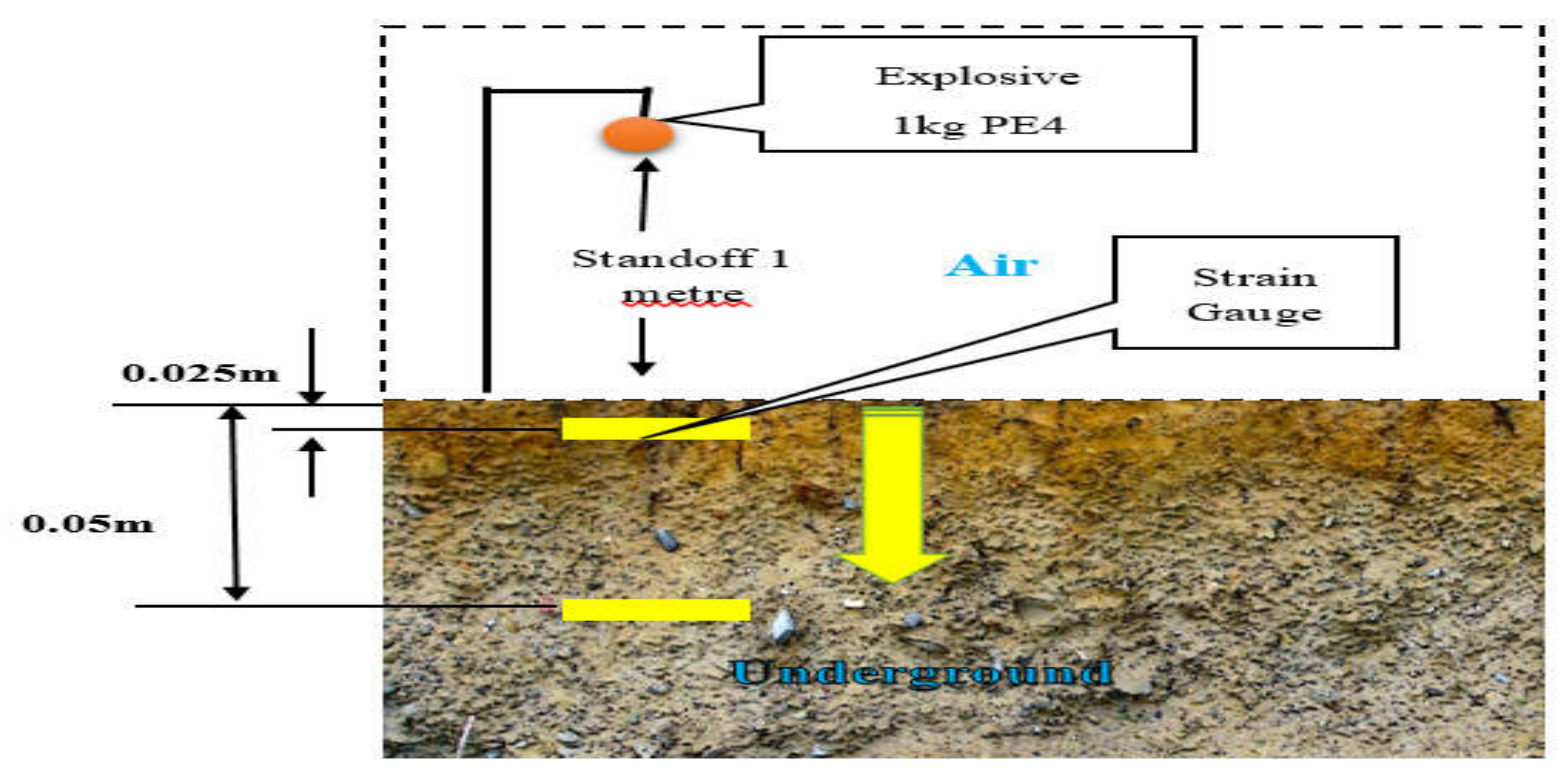

Fig.7. The proposed strain gage setup

\subsubsection{Field Blast Testing}

Fig. 8 depicts the test setup where the explosive material was fixed at 1-meter standoff from the ground surface prior to detonation process. Fig. 9 show the step by step procedures taken to place the strain gage sensor underneath the ground surface facing up to the explosive (1 meter above ground surface). Vishay Manganin type of strain gages were fixed to thin mild steel plates and was connected to NI SCXI 1520 Signal conditioner unit. PCB type of Pencil probe sensor was used to measure the spherical air blast peak pressure as reference. 


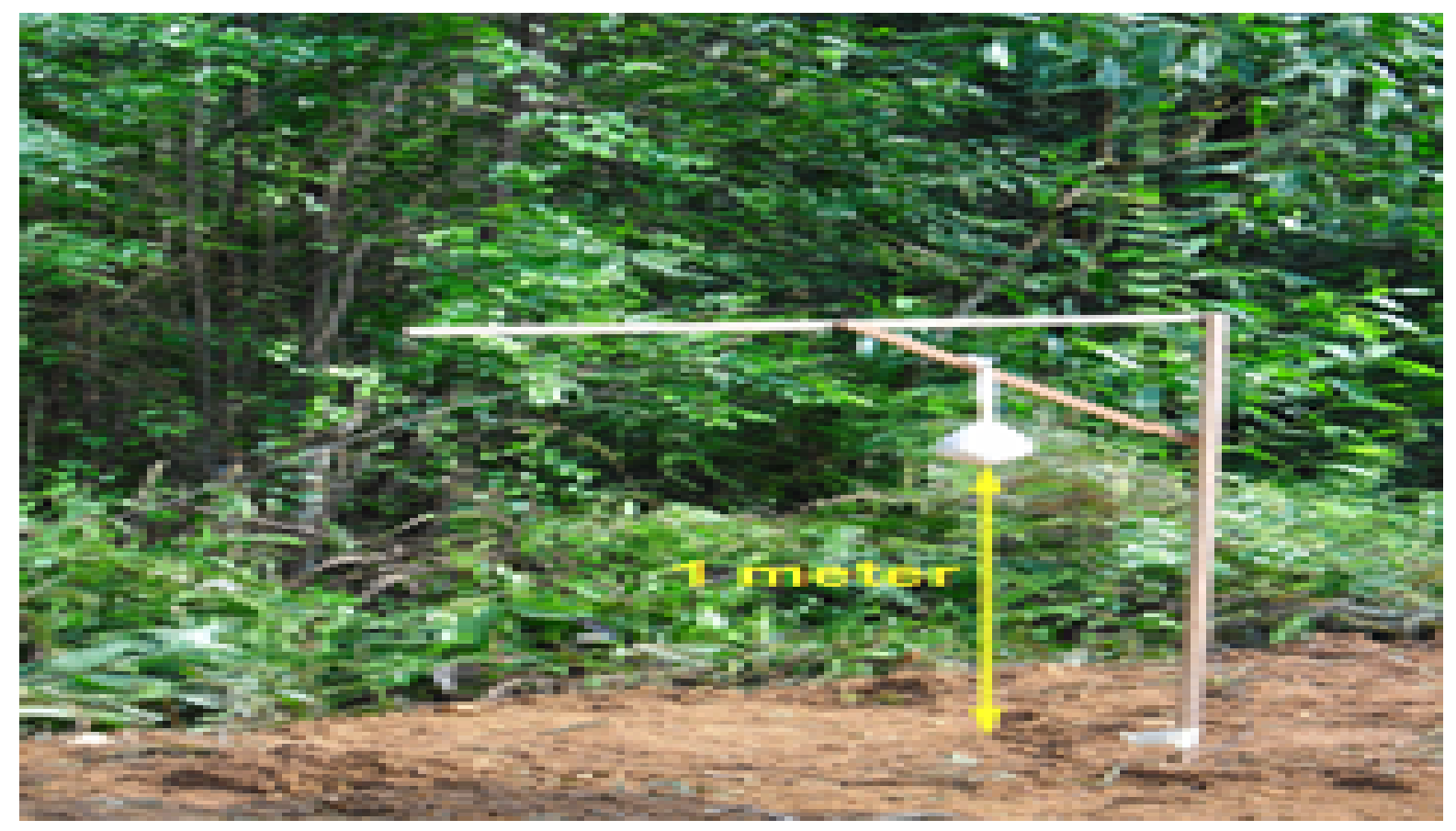

Fig.8. The standoff distance of explosive charge from ground

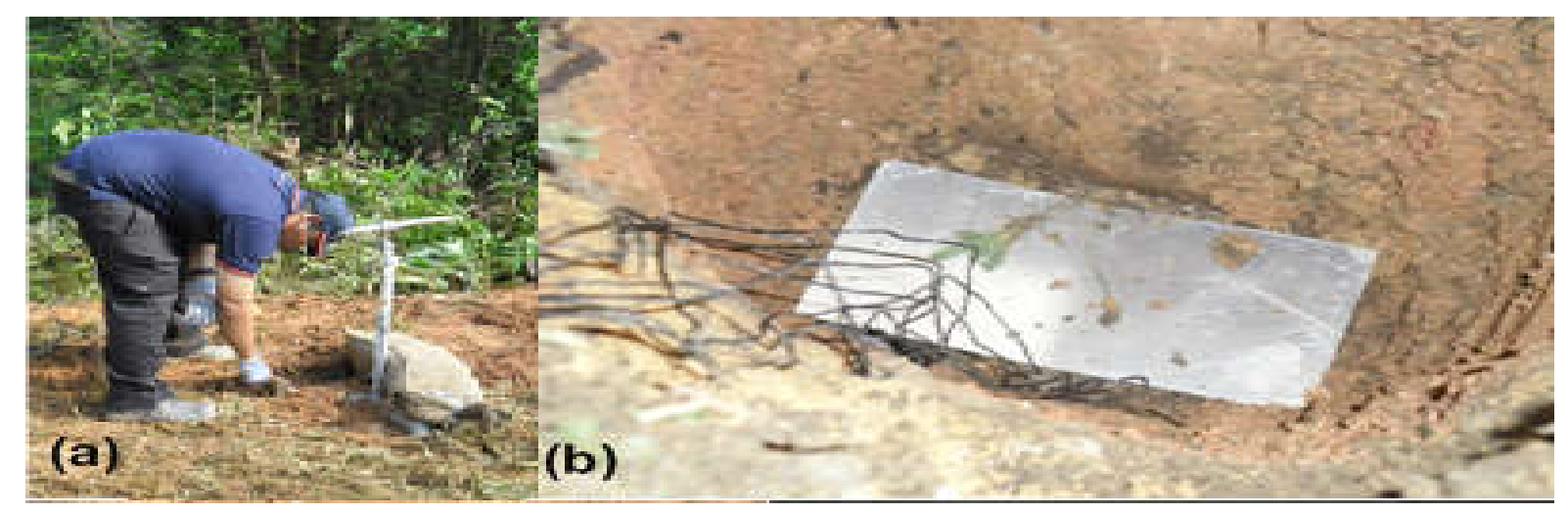

Fig.9. (a) ground leveling; (b) Strain gauge location

\subsection{Finite Element Analysis}

In order to study of the blast effect on the ground, the Arbitrary Lagrangian- Eulerian (ALE) method available in LSDYNA 3D software was used to simulate the blast wave from the air to the ground level. The soil structure boundary condition was modelled at 15 meter long and 1 meter width and at 1 meter soil depth. The explosive charge was modelled according to PE 4 material properties with $1 \mathrm{~kg}$ weight and radius of $0.054 \mathrm{~m}$.

\subsubsection{Soil Material Properties}

MAT_SOIL_AND_FOAM key card was used as the material model for the soil structure and the properties as shown in Table 1 define the material properties. 
Table 1. Soil material properties soil and foam [5]

\begin{tabular}{ccccccc}
\hline Mass & Shear & Bulk & Plastic & Plastic & Plastic & Pressure \\
Density, & Modulus, & Modulus, & Yields & Yields & Yields & Cutoff, \\
$(\rho) \mathbf{k g} / \mathbf{m}^{3}$ & $\mathbf{G}$ & $\mathbf{K}$ & Function, & Function, & Function, & PC \\
& & & $\mathbf{A 0}$ & $\mathbf{A 1}$ & $\mathbf{A 2}$ & \\
\hline 1800 & $6.39 \mathrm{e}-4$ & 0.0303 & $3.2 \mathrm{e}-13$ & $7.030 \mathrm{e}-7$ & 0.3 & $-6.9 \mathrm{e}-8$ \\
\hline
\end{tabular}

where $\rho$ is the mass density, $G$ is the shear modulus, $K$ is the bulk modulus, $A 0, A 1, A 2$ are yield function constant for plastic yield function below and $\mathrm{P}_{-}$cut is the pressure cut off for tensile fraction.

\subsubsection{Explosive PE4 Material Properties and Equation of State}

PE4 explosive material was modelled using MAT_HIGH_EXPLOSIVE_BURN available in LSDYNA 3D. This material card comprised of the equation of state, the Jones Wilkins Lee (JWL) EOS as shown in Table 2. Table 3 shows the equation of state JWL for explosive.

Table 2. Explosive material properties MAT_HIGH_EXPLOSIVE_BURN [6]

\begin{tabular}{ccc}
\hline $\begin{array}{c}\text { Mass Density, } \\
\boldsymbol{\rho}\left(\mathbf{k g} / \mathbf{m}^{\mathbf{3}}\right)\end{array}$ & $\begin{array}{c}\text { Detonation } \\
\text { Velocity, } \mathbf{D}(\mathbf{m} / \mathbf{s})\end{array}$ & $\begin{array}{c}\text { Chapman-Jouget } \\
\text { Pressure, } \mathbf{P C J}(\mathbf{P a})\end{array}$ \\
\hline 1601 & 8193 & $2.8 \mathrm{e} 10$ \\
\hline
\end{tabular}

Table 3. Font sizes for papers

\begin{tabular}{ccccccc}
\hline A & B & R1 & R2 & OMEG & E0 & V0 \\
\hline $6.098 \mathrm{e} 11$ & $1.295 \mathrm{e} 10$ & 4.5 & 1.4 & 0.25 & 5.639 & 1.0 \\
\hline
\end{tabular}

where A, B, R1, R2 and OMEG are constants pertaining to the explosive, $\mathrm{V}$ is relative volume, E0 is the initial energy per initial volume.

\subsubsection{Ambient Material Properties}

The MAT_NULL is used for model the air. The equation of state of the air is Linear Polynomial equation, the pressure calculates by the Equation (1) [7].

$\rho=C_{0}+C_{1 \mu}+C_{2 \mu^{2}}+C_{3 \mu^{3}}+\left(C_{4}+C_{5 \mu}+C_{6 \mu^{2}}\right) E$

where $\mu=\rho / \rho_{0}^{-1}$, where $\rho / \rho_{0}^{-1}$ is the ratio of current density and the initial density. Where air is idea gas, $C_{0}=C_{1}=C_{2}=C_{3}=C_{6}=0$ and $C_{4}=C_{5}=\gamma-1 . \gamma$ is the specific heat capacity of the gas, generally takes air density $1.292 \mathrm{~kg} . \mathrm{m} 3$, the initial internal density $E$ is 
$0.25 \mathrm{MJ} / \mathrm{m}^{3}$

\section{CONCLUSION}

From the study, it can be concluded the experimental results showed a higher difference percentages compared to the computed numerical data. This difference may be due to the instrumentation noise that may influenced the recorded experimental data. Both force and acceleration data showed that the blast wave decreases with the propagation depth. This may be due to the dissipation of energy as the wave travels through the soil structure.

\section{ACKNOWLEDGEMENTS}

The authors wish to acknowledge the research grant provided by Long Term Research Grant Scheme (LRGS) LRGS/B-U/2013/UPNM/DEFENCE\&SECURITY-P3 from the Malaysian Ministry of Education that lead to the realization of this work.

\section{REFERENCES}

[1] Tan L B, Kwong M T, Vincent B C T, Heow P L. Finite element modeling of buried glass-reinforced composite pipe. In 10th International Conference on Composite Science and Technology, 2015, pp. 1-14

[2] Deshpande V S, McMeeking R M, Wadley H N G, Evans A G. Constitutive model for predicting dynamic interactions between soil ejecta and structural panels. Journal of the Mechanics and Physics of Solids, 2009, 57(8):1139-1164

[3] Chafi M S, Karami G, Ziejewski M. Numerical analysis of blast-induced wave propagation using FSI and ALEmulti-material formulations. International Journal of Impact Engineering, 2009, 36(10):1269-1275

[4] De A. Numerical simulation of surface explosions over dry, cohesionless soil. Computers and Geotechnics, 2012, 43:72-79

[5] Kulak R F. Modeling of cone penetration test using SPH and MM-ALE approaches. In 8th European LS-DYNA Users Conference, 2011, pp. 1-10

[6] Bogosian D, Yokota M, Rigby S E. TNT equivalence of C-4 and PE4: A review of 
traditional sources and recent data. In 24th Military Aspects of Blast and Shock, 2016, pp. $1-15$

[7] Cheng D, Hung C, Pi S. Numerical simulation of near-field explosion. Journal of Applied Science and Engineering, 2013, 16(1):61-67

\section{How to cite this article:}

Hafizi MN, Risby MS, Umar ST, Isa MFM, Sohaimi ASM, Khalis S.Experimental and numerical investigation on blast wave propagation in soil structure. J. Fundam. Appl. Sci., 2017, 9(3S), 221-230. 